\title{
Effects of Altered Glucose Homeostasis on Glucose Transporter Expression in Skeletal Muscle of the Rat
}

Raymond E. Bourey, Laszlo Koranyi, David E. James,“ Mike Mueckler, ${ }^{*}$ and M. Alan Permutt

Department of Medicine and ${ }^{*}$ Department of Cell Biology, Washington University School of Medicine, St. Louis, Missouri 63110

\begin{abstract}
Previous studies have suggested that alteration in the expression of the insulin-regulatable glucose transporter of muscle (GLUT-4 protein) may be an important determinant of insulin action. In the present studies, we have examined GLUT-4 mRNA and protein concentrations in muscle after variations in the metabolic status of the intact animal (i.e., $7 \mathrm{~d}$ streptozotocin-induced diabetes, $7 \mathrm{~d}$ insulin-induced hypoglycemia, and 3 d fasting). These changes in glucose homeostasis were associated with the following changes in GLUT-4 gene products: a decrease of $\sim 30 \%$ in both mRNA and protein with diabetes; a $50 \%$ increase in mRNA and a 2.4-fold increase in protein with insulin injection; and normal mRNA in spite of a 2.7-fold increase in protein with fasting. Fasted diabetics exhibited an increase of $50 \%$ in GLUT-4 mRNA and a 2.4 -fold increase in protein relative to fed diabetics. In diabetic and insulin-injected groups, the changes in GLUT-4 protein were similar to changes in mRNA, but in fasting, GLUT-4 protein increased without a concomitant change in mRNA. Overall there was no correlation between muscle concentrations of GLUT- 4 protein and mRNA. Muscle GLUT-4 protein concentration tended to correlate with plasma glucose $(r=-0.57, P<0.001)$, but not with plasma insulin. These results indicate that $(a)$ chronic changes in glucose homeostasis are associated with changes in expression of GLUT-4 protein in muscle; (b) GLUT- 4 protein increased in fasted soleus muscle without change in mRNA, thereby differing from fasted adipocytes in which both GLUT-4 products diminish; and (c) no simple relationship exists between total muscle GLUT-4 protein content and whole-body insulin sensitivity. (J. Clin. Invest. 1990. 86:542547.) Key words: GLUT-4 gene • rat soleus • fasting • diabetes • hypoglycemia
\end{abstract}

\section{Introduction}

Skeletal muscle plays an important role in the clearance of a systemic glucose load $(1,2)$, and a decreased response to insulin of muscle glucose transport and utilization contributes to the manifestation of whole-body insulin resistance (1). The major glucose transporter gene of muscle and adipose tissue (GLUT-4) has recently been cloned and its product characterized as a 43-kD, membrane-spanning protein (3-7). As glucose

Address reprint requests to Dr. M. Alan Permutt, Department of Medicine, Washington University School of Medicine, 660 South Euclid Ave., Box 8127, St. Louis, MO 63110.

Received for publication 2 November 1989 and in revised form 24 April 1990.

J. Clin. Invest.

(c) The American Society for Clinical Investigation, Inc.

$0021-9738 / 90 / 08 / 542 / 06 \$ 2.00$

Volume 86, August 1990, 542-547 transport is the first and probably rate-limiting step of muscle glucose utilization (8), the muscle glucose transporter has been identified as a potential site for the development of insulin resistance $(8,9)$. The expression of the GLUT-4 gene and activity of the GLUT-4 protein has therefore been subjected to intense study.

A unique feature of GLUT-4 compared with other glucose transporter genes is that its expression appears to be confined to muscle and adipose tissue $(3,4)$. GLUT- 4 mRNA and protein concentrations have recently been studied in adipose tissue obtained from streptozotocin (STZ)-treated ${ }^{1}$ diabetic rats (9-12). These studies demonstrated a marked decrease in GLUT-4 gene products; hence, it was concluded that the plasma insulin concentration is an important regulator of GLUT-4 expression. These studies, however, did not distinguish between lack of insulin per se and the metabolic consequences of lack of insulin as potential regulators of GLUT-4. Furthermore, we recently found that changes in adipocyte GLUT -4 mRNA are not always associated with similar changes in muscle (13), and one cannot assume that adipose cell and skeletal muscle expression of GLUT-4 will respond in the same manner to metabolic perturbations.

That GLUT- 4 content may be regulated at the pretranslational level in muscle was recently demonstrated by Garvey et al. (9), who reported a significant decline in GLUT-4 mRNA in quadriceps femoris muscles of rats with STZ-induced diabetes. The content of muscle GLUT-4 mRNA rose toward control values with insulin therapy (9). Although previous studies have demonstrated a decrease in diabetic muscle glucose transporter binding of cytochalasin B (14), the variation in and relationship between muscle GLUT-4 mRNA and transporter protein content under various conditions is unknown.

To further elucidate the physiological factors that might control the expression of muscle glucose transporter, we exposed animals to conditions known to produce disparate levels of blood insulin and glucose and alterations in muscle glucose transport. We found that muscle GLUT-4 expression varies with perturbations in glucose homeostasis, and, in contrast to previous findings in the adipocyte, in a manner not directly related to plasma insulin concentrations.

\section{Methods}

Animals. Male Sprague-Dawley rats ( 150 g) from SASCO (Omaha, $\mathrm{NE}$ ) fed a standard diet of rat chow (Ralston Purina Co., St. Louis, MO) were used. After $7 \mathrm{~d}$ of acclimation to our animal facility, the animals were divided into the following experimental groups of six animals: $(a)$ Control, $(b)$ STZ-induced diabetic, $(c)$ insulin-injected hypoglycemic, $(d)$ fasted, and $(e)$ fasted, STZ-induced diabetic.

Diabetes was induced by a single intraperitoneal injection of STZ

1. Abbreviations used in this paper: STZ, streptozotocin. 
(75 mg $\cdot \mathrm{kg}$ body $\mathrm{wt}^{-1}$; Sigma Chemical Co., St. Louis, MO). The animals were observed for $7 \mathrm{~d}$ and the existence of diabetes was confirmed by daily measurement of blood glucose.

Hypoglycemia was produced by daily subcutaneous insulin injection (ultralente, $40 \mathrm{U} \cdot \mathrm{kg}$ body $\mathrm{wt}^{-1} \cdot \mathrm{d}^{-1}$; Squibb-Novo, Princeton, $\mathrm{NJ}$ ) for $7 \mathrm{~d}$. Blood glucose levels were measured every morning and the insulin dose was adjusted to maintain the blood glucose at 60-70 $\mathrm{mg} \cdot \mathrm{dl}^{-1}$ for $3 \mathrm{~d}$ before analysis. Two animals required an upward adjustment in insulin dose during the final $48 \mathrm{~h}$.

Six control and six diabetic rats were individually housed and fasted for $3 \mathrm{~d}$.

Blood and tissue sampling. The control, diabetic, and hypoglycemic animals were killed in the fed state, and the fasted and diabeticfasted animals in the fasted state using sodium pentobarbital (100 $\mathrm{mg} \cdot \mathrm{kg}$ body $\mathrm{wt}^{-1}$ i.p.). Before injection, whole blood was collected from tail veins in heparinized tubes. Before respiratory arrest, the soleus muscle from each leg was removed intact, clamp-frozen in liquid nitrogen, and stored at $-80^{\circ} \mathrm{C}$ until analysis.

Plasma analysis. Daily heparinized blood samples were analyzed for plasma glucose by an automated glucose oxidase method (Beckman Instruments Inc., Fullerton, CA). Plasma insulin concentrations were determined by a double-antibody RIA using rat insulin standards.

Determination of muscle glucose transporter mRNA content. The probes used for study were as follows: (a) GLUT-1 glucose transporter cDNA from a HepG2 cDNA library (15); (b) GLUT-4 cDNA, isolated from rat adipocyte and heart cDNA libraries as described (4); and $(c)$ a plasmid containing 1,200 bp of chicken beta-actin cDNA. Each plasmid was subcloned in Bluescript SK ${ }^{+}$(Stratagene, La Jolla, CA), an RNA expression vector. Transcription of uniformly labeled ${ }^{32} \mathrm{P}$-cRNA and synthetic mRNA with $T_{3}$ or $T_{7}$ RNA polymerase was performed according to protocols provided by the supplier.

Total tissue RNA was extracted using a guanidine thiocyanate method (16). All samples had $28 \mathrm{~S}: 18 \mathrm{~S}$ ratios $>2.0$ on ethidium bromide staining after electrophoresis on agarose gels and also showed discrete mRNA bands on Northern blot analysis.

Initial studies to validate the specificity of each CRNA probe were performed using Northern analysis. Once the appropriate stringency for hybridization of each clone was established, quantitation of mRNA levels between rats was performed using dot blot analysis. Aliquots of total tissue RNA (1-10 $\mu \mathrm{g})$ and dilutions of synthetic mRNA $(0.5-1,000 \mathrm{pg})$ and cDNA $(1-1,000 \mathrm{pg})$ as standards were dissolved in $15 \%$ formaldehyde in $10 \times$ SSC and blotted onto Nytran (Schleicher \& Schuell, Inc., Keene, NH) membranes. Membranes were hybridized to the corresponding probes for $16-18 \mathrm{~h}$ (GLUT- 1 and GLUT-4 at $60^{\circ} \mathrm{C}$, actin at $55^{\circ} \mathrm{C}$ ) in $50 \%$ formamide in $5 \times$ SSPE and then washed (GLUT- 1 and GLUT -4 at $60^{\circ} \mathrm{C}$, actin at $52^{\circ} \mathrm{C}$ ) in $0.1 \times$ SSC, $0.1 \%$ SDS, according to instructions recommended by the vendor. Blots were exposed to Kodak XAR5 film at $-80^{\circ} \mathrm{C}$ with intensifying screens (Cronex Lightning Plus; E. I. DuPont de Nemours Co., Wilmington, DE). The amount of mRNA present in each sample, determined in duplicate, was measured by densitometric analysis, comparing the intensity of the sample dot to standard dots. Autoradiographs were developed for various periods of time so that the intensity of the unknown samples was within the linear range of the standards.

Immunoblotting. Muscle was homogenized (Brinkmann Instruments, Inc., Westbury, NY) on ice at high speed for $45 \mathrm{~s}$ in PBS at $\mathrm{pH}$ 7.4 with $0.5 \%$ deoxycholate and $0.5 \%$ Triton X-100 (1:20, wt/vol). Aliquots of the homogenized samples were diluted 1:16 in PBS at pH 7.4 and protein concentration was determined by a modification of the method of Lowry (17). 50 or $100 \mu \mathrm{g}$ per lane of protein was subjected to SDS-PAGE. For each gel, samples from an experimental group were placed in alternating lanes with samples from the control group. Protein was electrophoretically transferred (Polyblot; ABN, Hayward, CA) to nitrocellulose paper. Nitrocellulose sheets were incubated with PBS containing $50 \mathrm{mg} / \mathrm{ml}$ powdered milk (Carnation Co., Los Angeles, CA) for $90 \mathrm{~min}$ at $22^{\circ} \mathrm{C}$, incubated with a polyclonal antibody (R820, 10 $\mu \mathrm{g} / \mathrm{ml}$ PBS) specific for the GLUT-4 carboxy terminus (4), washed, incubated for $1 \mathrm{~h}$ with $2.5 \mu \mathrm{Ci}{ }^{125} \mathrm{I}$-labeled protein A, rewashed, dried, and subjected to autoradiography. Quantitation was performed by excising labeled bands and counting in a gamma counter (Packard Instrument Co., Inc., Downers Grove, IL). Equal areas away from the band of interest were excised and analyzed to establish background. The mean counts per minute above background per lane was $685 \pm 57$ (SE). The value in counts per minute obtained for each sample was divided by the mean of the six control values for the blot to allow direct comparison between blots. The intra- and interblot coefficients of variation for this method were, respectively, 13\% (the same sample in 12 adjacent lanes) and 35\% (the same sample in nine separate blots).

Data analysis. Data were managed and analyzed on the CLINFO system of the Washington University Clinical Research Center (GCRC RR00036). The data were analyzed by analysis of variance and differences between groups were identified by the Newman-Keuls post hoc test. The analysis of the immunoblots was performed by an unpaired $t$ test as one experimental group was directly compared with a control group on each blot (v.s.). When protein from control, diabetic, and fasted diabetic animals was analyzed on the same immunoblot to directly compare diabetic and fasted diabetic samples, comparisons were performed by analysis of variance. Correlations were analyzed by univariate linear regression analysis.

\section{Results}

Physiological characteristics. Final body weights, weight changes, and plasma glucose and insulin concentrations before tissue removal are shown in Table I. After $7 \mathrm{~d}$ of STZ-induced diabetes, animals did not gain a significant amount of weight and thus differed from control animals. Their plasma insulin concentration was not different from control values in spite of marked hyperglycemia. Fasting of diabetic animals was asso-

Table I. Plasma Glucose and Insulin

\begin{tabular}{lccccc}
\hline \multicolumn{1}{c}{ Group } & Control & Diabetic & $\begin{array}{c}\text { Insulin-injected } \\
\text { hypoglycemic }\end{array}$ & Fasted & $\begin{array}{c}\text { Diabetic } \\
\text { fasted }\end{array}$ \\
\hline Final body weight, $g$ & $251 \pm 5$ & $198 \pm 5^{*}$ & $246 \pm 5$ & $178 \pm 5^{*}$ & $155 \pm 5^{*}$ \\
Body weight change, $g^{\ddagger}$ & $59 \pm 4$ & $6 \pm 3^{*}$ & $58 \pm 5$ & $-36 \pm 5^{*}$ & $-36 \pm 4^{* \S}$ \\
Plasma glucose, $m M^{\| 1}$ & $7.4 \pm 0.4$ & $23.4 \pm 3.2^{*}$ & $4.4 \pm 0.6$ & $6.1 \pm 0.2$ & $5.6 \pm 0.8^{\S}$ \\
Plasma insulin, $p M$ & $170 \pm 20$ & $180 \pm 40$ & $930 \pm 350^{*}$ & $90 \pm 40$ & $120 \pm 10$
\end{tabular}

Values are expressed as mean $\pm \mathrm{SE} ; n=6$ for each group. ${ }^{*}$ Differs from control value, $P<0.05$. ${ }^{\ddagger}$ Final minus initial weight for experimental period. (i.e., $7 \mathrm{~d}$ for control, diabetic, and insulin-injected diabetic; $3 \mathrm{~d}$ for fasted and diabetic groups). ${ }^{\S}$ Differs from diabetic value, $P$ $<0.05$. "Values of final glucose determination at the time of tissue analysis except insulin-injected hypoglycemic group, which represents the mean glucose value for $72 \mathrm{~h}$ before analysis. 


\begin{tabular}{|c|c|c|c|c|c|}
\hline Group & Control & Diabetic & $\begin{array}{l}\text { Insulin-injected } \\
\text { hypoglycemic }\end{array}$ & Fasted & $\begin{array}{l}\text { Diabetic } \\
\text { fasted }\end{array}$ \\
\hline Soleus weight, $m g$ & $95 \pm 3$ & $88 \pm 5$ & $111 \pm 9 *$ & $92 \pm 3$ & $74 \pm 4$ \\
\hline Total RNA, mg/g tissue & $1.08 \pm 0.09$ & $1.10 \pm 0.13$ & $0.98 \pm 0.05$ & $0.88 \pm 0.05$ & $0.97 \pm 0.06$ \\
\hline Total protein, $m g / g$ tissue & $13.6 \pm 1.9$ & $13.8 \pm 1.4$ & $14.5 \pm 2.8$ & $14.2 \pm 0.9$ & $14.3 \pm 1.5$ \\
\hline Actin mRNA, $p g / \mu g R N A$ & $530 \pm 30$ & $470 \pm 60$ & $510 \pm 40$ & $270 \pm 70^{*}$ & $310 \pm 80$ \\
\hline HepG2 mRNA, pg/ $\mu g R A$ & $1.2 \pm .2$ & $1.0 \pm .1$ & $1.2 \pm .3$ & $1.1 \pm .3$ & $1.7 \pm .2$ \\
\hline
\end{tabular}

Values are mean $\pm \mathrm{SE} ; n=6$ for all groups. ${ }^{*}$ Different from control value; $P<0.05$.

ciated with a decrease in plasma glucose concentrations to values not different from those of control animals. Although the insulin-injected animals appeared to eat without regard for the light cycle, the weight change did not differ from that in control animals. Insulin injection produced prolonged hyperinsulinemia and hypoglycemia. Fasting of control animals was associated with weight loss and decreased glucose concentrations.

Muscle characteristics. Muscle weight, content of RNA and protein, and concentrations of actin MRNA and GLUT-1 (Hep G2, erythrocyte, and brain) mRNA are noted in Table II. The muscle weight did not vary among the treatment groups except in insulin-injected, hypoglycemic animals in which it was increased. The soleus muscle weight expressed as percent of body weight was increased $(P<0.05)$ in the fasted $(0.051 \pm 0.001 \%)$ and fasted-diabetic $(0.048 \pm 0.002 \%)$ animals when compared with controls $(0.038 \pm 0.002 \%)$. Total RNA and protein content were not different among groups.

We performed quantitative dot blots to measure mRNA levels for actin, GLUT-1, and GLUT-4. We used actin mRNA as a control for changes in glucose transporter mRNA. There was no change in actin mRNA with STZ-induced diabetes or insulin injection. When animals were fasted, however, there was a 50\% decrease in actin mRNA. Interestingly, GLUT-1 mRNA did not diminish with fasting and did not vary with metabolic state. GLUT-1 was present at only $1 \%$ the level of GLUT-4 mRNA, and we have been unable to detect the GLUT-1 protein in skeletal muscle using an antibody specific for the carboxy terminus of the rat brain glucose transporter sequence (data not shown).

A polyclonal antibody (R820) specific for the carboxy terminus of the GLUT-4 sequence was used to detect this protein in muscle homogenates (4). Consistent with previous studies $(3-7,9,10,12)$ a $\sim 45-k D$ immunoreactive species was detected, and examples of immunoblots used to assay muscle GLUT-4 protein concentration are presented in Fig. 1. GLUT-4 mRNA and protein concentrations are presented in

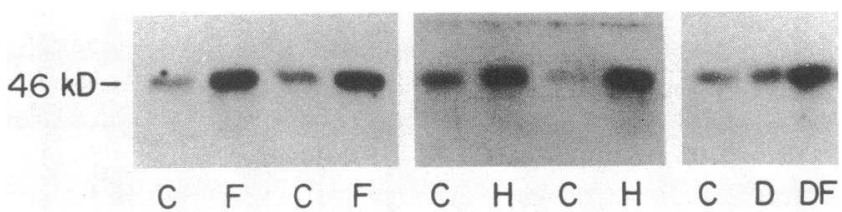

Figure 1. Samples of radiographs of Western blots with lanes of protein samples from control $(C)$, fasted $(F)$, insulin-injected, hypoglycemic $(H)$, STZ-induced diabetic $(D)$, and fasted diabetic $(D F)$ animals.
Fig. 2. After $7 \mathrm{~d}$ of STZ-induced diabetes, there was a $30 \%$ decrease in GLUT-4 protein and a tendency to a similar decrease in GLUT -4 mRNA. When diabetic animals were fasted, the GLUT- 4 protein concentration increased $140 \%$ to a level $70 \%$ higher than control values. Prolonged insulin-induced hypoglycemia was associated with a $50 \%$ increase in GLUT-4 mRNA and a 2.4-fold increase in GLUT-4 protein concentration. Fasting of controlled animals was associated with no change in GLUT-4 mRNA but a striking 2.7 -fold increase in GLUT-4 protein.

Though changes in GLUT-4 protein concentration were qualitatively similar to changes in GLUT-4 mRNA in diabetic and insulin-injected groups, the concentrations of GLUT-4 protein in the fasted groups were markedly increased in spite of normal concentrations of GLUT-4 mRNA, and overall there was no correlation between muscle GLUT-4 mRNA and GLUT-4 protein concentrations. Muscle GLUT-4 protein concentration tended to correlate with plasma glucose concentration $(r=0.57, P<0.001)$, but there was no correlation with plasma insulin concentration $(r=0.08, P=0.67)$.

As muscle RNA and protein content did not vary (Table II), concentrations of mRNA species and GLUT-4 protein reflect the muscle content of these gene products expressed per gram of tissue. In addition, concentrations of GLUT-4 mRNA and protein also reflect the total muscle content of these species with the exception of the fasted-diabetic group, in which total muscle content of GLUT-4 protein is not different from control values.

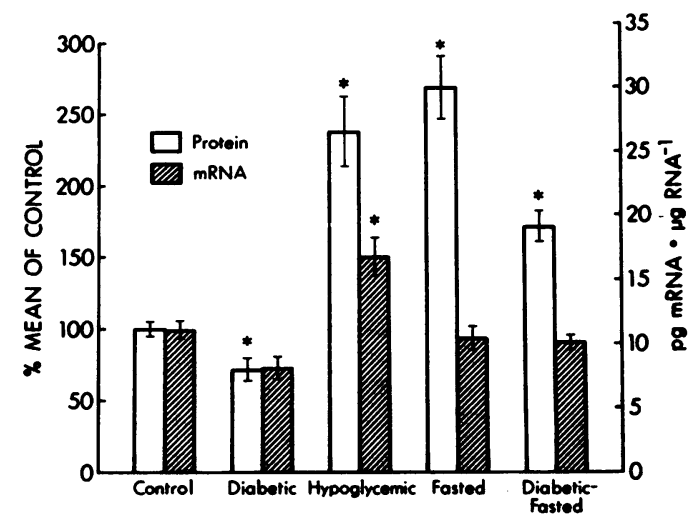

Figure 2. Concentrations of GLUT-4 protein and mRNA determined as described in Methods and expressed as mean \pm SE for control $(C)$, STZ-induced diabetic $(D)$, insulin-injected, hypoglycemic $(H)$, fasted $(F)$, and fasted diabetic $(D F)$ animals. ${ }^{*}$ Different from control value, $P<0.05$. 


\section{Discussion}

As muscle glucose transporter is a prime candidate for regulation of whole-body insulin resistance or sensitivity, we studied the muscle content of transcriptional and translational products of the GLUT-4 gene under conditions known to produce disparate levels of glucose, insulin, and insulin resistance. We found that modulation of the transporter mRNA and protein occurs in conditions of STZ-induced diabetes mellitus, insulin-induced hypoglycemia, and fasting.

After $7 \mathrm{~d}$ of STZ-induced diabetes, the concentration of GLUT-4 protein in the soleus muscle was decreased $~ 30 \%$ compared with control values. Our findings are consistent with previous reports for muscle GLUT-4 mRNA (9) and glucose transporter protein estimated by cytochalasin B binding (14). Interestingly, the decrease in total muscle glucose transporter of the diabetic state is associated with a decrease in insulinstimulated glucose disposal, whether measured in vivo by means of the euglycemic clamp technique $(1,18)$, or in isolated muscle in vitro $(19,20)$. Soleus GLUT-4 mRNA concentration tended to decrease similarly to protein and independently of actin and GLUT-1 mRNA, which did not change. These results are consistent with the hypothesis that chronic regulation of muscle glucose transporter content in diabetes occurs at a pretranslational level (9). No conclusion about transcriptional regulation per se may be drawn, however, without measurement of turnover of transcriptional products.

Recent studies (9-12) suggested that insulin was the primary determinant of chronic changes in GLUT-4 products. However, plasma insulin concentrations of our diabetic animals, though insufficient to maintain euglycemia, were normal (Table I), yet GLUT-4 protein was depressed. Ramlal et al. (14) found a similar decrease in muscle glucose transporter content as measured by cytochalasin B binding in normoinsulinemic, STZ-treated diabetic rats, and suggested a role for hyperglycemia in muscle glucose transporter regulation. Our finding that correction of hyperglycemia by fasting diabetic animals was associated with a $50 \%$ increase in the concentration of GLUT-4 mRNA to normal and GLUT-4 protein levels to supernormal further suggests that ambient glucose concentration and not insulin may be more closely associated with the decrease of GLUT -4 products in diabetic states. Similarly, phlorizin treatment has been shown to correct not only hyperglycemia, but also whole-body insulin resistance in rats made diabetic by partial pancreatectomy (18). A lesser role for insulin would also be compatible with recent observations that insulin treatment does not increase the content of GLUT-4 mRNA in cultured 3T3-L1 adipocytes (21). These findings suggest that hyperglycemia may be a factor in downregulation of GLUT-4 mRNA, protein, and insulin-stimulated glucose disposal in diabetes.

We found that insulin-injected, hypoglycemic animals, in contrast to diabetics, had a marked increase in GLUT-4 mRNA and protein concentration. Adipocytes from insulininfused, hypoglycemic animals had a similarly increased total glucose transporter number by cytochalasin B binding (22) and also increased insulin-stimulated glucose uptake in vitro (22-24). The findings of Wardzala et al. (23) that soleus muscle strips from insulin-infused rats have enhanced insulinstimulated glucose metabolism and glycogen synthase activity suggest that muscle may have similarly enhanced insulin-stim- ulated glucose disposal in vitro. Our finding of increased GLUT-4 mRNA and protein in skeletal muscle of insulin-injected hypoglycemic rats is also compatible with the hypothesis that in vitro insulin resistance or sensitivity of muscle may be at least partially regulated at the pretranslational level through chronic changes in GLUT-4 number.

Fasted animals, like insulin-injected animals, are hypoglycemic and have a marked increase in soleus muscle GLUT-4 protein concentration (Fig. 2), and Brady et al. (25) previously demonstrated enhanced insulin-stimulated uptake in perfused hindlimbs or soleus muscles from 48-h fasted rats. Unlike insulin-injected animals, however, fasted animals exhibited no increase in muscle GLUT-4 mRNA content, a finding that may be consistent with a role for insulin in regulating pretranslational changes of soleus GLUT -4 products. The absence of a correlation between muscle GLUT-4 mRNA and GLUT-4 protein is in distinct contrast to our results for brain glucose transporter, in which both GLUT-1 glucose transporter protein and mRNA content increased after a 72-h fast (Koranyi, L., R. E. Bourey, D. E. James, M. Mueckler, F. T. Fiedorek, Jr., and M. A. Permutt, manuscript submitted for publication). Discordance between GLUT-4 mRNA and protein has previously been described in adipocytes from insulintreated diabetic rats (10). The apparent accumulation of GLUT-4 protein in muscle with fasting may be due to increased efficiency of mRNA translation and/or decreased transporter degradation. As soleus muscle glucose transport and total protein synthesis is diminished in fasting $(26,27)$, the latter mechanism seems more likely. Similarly, glucose deprivation of 3T3-L1 adipocytes has been associated with stabilization of the GLUT-4 protein (Tordjman, K., and M. Mueckler, unpublished data). It is interesting that soleus muscle content of both GLUT-1 and GLUT-4 mRNA, members of the facilitative glucose transporter gene family, remained at normal levels with fasting and appeared spared compared with actin mRNA, which was reduced by $40 \%$. Mechanisms that induce changes in GLUT-4 mRNA with diabetes or insulin injection may be different from the mechanism(s) responsible for the lack of change in GLUT-4 (and GLUT-1 mRNA) with fasting.

In contrast to diabetes, where changes in muscle GLUT-4 mRNA and protein were concordant with changes previously described for adipocytes (9-12), with fasting, several differences were apparent between regulation of glucose transporters in adipocytes and regulation in skeletal muscle. In distinct contrast to the soleus muscle, fasting resulted in a diminished adipocyte content of GLUT-1 mRNA (28), GLUT-4 mRNA (11), GLUT-4 protein (12), and insulin-stimulated glucose transport in vitro $(9,28)$. Furthermore, fasting resulted in a marked decrease in adipocyte size (28), whereas working muscles such as the soleus were spared this wasting effect (27; Table I). At least in fasting, GLUT-4 products appear to be regulated differently in fat cells and muscle.

Although our observed changes in total muscle glucose transporter content appear related to previously described changes in muscle insulin-stimulated glucose uptake measured in vitro $(19,20,22,25)$, these changes are not necessarily related to changes in insulin-stimulated glucose disposal at the whole-body level. In theory, insulin-stimulated glucose disposal may be limited in vivo by glucose delivery to the tissue, membrane glucose transport, or metabolic glucose disposal. Furthermore, muscle glucose transporters are not functionally 
active until translocated from an intracellular pool to the plasma membrane. When measured under the stable conditions of the euglycemic clamp technique, all three experimental states (diabetes [1, 18], insulin injection [29], and fasting [30]) were associated with evidence of whole-body insulin resistance. Results of in vivo and in vitro studies of diabetics are in general agreement, but decreases in whole-body, insulinstimulated glucose disposal in fasted and insulin-injected animals, in spite of in vitro increases in muscle insulin sensitivity, underscore the complexity of glucose homeostasis and preclude a simple relationship between total muscle GLUT-4 concentrations and whole-body insulin resistance.

The mechanism by which the glucose concentration of plasma is related to an intracellular event (i.e., changes in total glucose transporter number) cannot be directly determined from these studies. In theory, glucose transport would be expected to correlate best with the number of cell surface transporters, and insulin resistance would indicate a decrease in the number of transporters translocated to the cell surface in response to insulin. Any of the metabolic consequences of pancreatic beta cell dysfunction that lead to hyperglycemia are potential regulators of GLUT-4. The disproportionate increase in muscle glucose transporter compared with GLUT-4 mRNA in fasted and insulin-injected, hypoglycemic animals would be compatible with the hypothesis that hypoglycemic counterregulatory hormones, or some factor of the hypoglycemic plasma milieu, inhibit cell turnover of muscle glucose transporter and perhaps its translocation to a functional position in the sarcolemma. The presence of an inhibitor of muscle GLUT-4 translocation in hypoglycemic plasma but not in vitro perfusion media would explain the paradox in fasted and insulininjected animals of decreased insulin-stimulated glucose disposal in vivo but increased insulin-stimulated glucose disposal in vitro.

In summary, the results of these studies clearly indicate that the mechanisms for modulation of muscle glucose transporter content vary with the physiological state. Whether plasma glucose, insulin, and/or other metabolic factors are the primary determinants of the changes observed in these studies has yet to be determined. We believe it is important to experimentally separate these factors and their relative contributions to expression and function of the muscle glucose transporter, as the findings may have a profound influence on our treatment of type II diabetes mellitus and other insulin-resistant states.

\section{Acknowledgments}

This work was supported in part by National Institutes of Health (NIH) Research Service Awards AG-00078 to Dr. Bourey and DK-07140 to Dr. Bourey, NIH grants DK-16746 to Dr. Permutt and DK-38495 to Dr. Mueckler, and Juvenile Diabetes Association Research Fellowship 387269 to Dr. Koranyi. Dr. James and Dr. Permutt are recipients of research grants and Dr. Mueckler is a recipient of a Career Development Award from the Juvenile Diabetes Foundation.

\section{References}

1. DeFronzo, R. A., R. Gunnarsson, O. Bjorkman, M. Olsson, and J. Wahren. 1985. Effects of insulin on peripheral and splanchnic glucose metabolism in non-insulin dependent (type II) diabetes mellitus. J. Clin. Invest. 76:149-155.
2. Kelley, D., A. Mitrakou, H. Marsh, F. Schwenk, J. Benn, G. Sonnenberg, M. Archangeli, T. Aoki, J. Sorenson, M. Berger, P. Sonksen, and J. Gerich. 1988. Skeletal muscle glycoslysis, oxidation, and storage of an oral glucose load. J. Clin. Invest. 81:1563-1571.

3. James, D. E., R. Brown, J. Navarro, and P. F. Pilch. 1988. Insulin-regulatable tissues express a unique insulin-sensitive glucose transport protein. Nature (Lond.). 333:183-185.

4. James, D. E., M. Strube, and M. Mueckler. 1989. Molecular cloning and characterization of an insulin-regulatable glucose transporter. Nature (Lond.). 338:83-87.

5. Birnbaum, M. J. 1989. Identification of a novel gene encoding an insulin-responsive glucose transporter protein. Cell. 57:305-315.

6. Charron, M. J., F. C. Brosius, S. L. Alper, and H. F. Lodish. 1989. A glucose transport protein expressed predominately on insulin-responsive tissues. Proc. Natl. Acad. Sci. USA. 86:2535-2539.

7. Fukumoto, H., T. Kayano, J. B. Buse, Y. Edwards, P. F. Pilch, G. I. Bell, and S. Seino. 1989. Cloning and characterization of the major insulin-responsive glucose transporter expressed in human skeletal muscle and other insulin-responsive tissues. J. Biol. Chem. 264:776-779.

8. Ziel, F. H., N. Venkatesan, and M. B. Davidson. 1988. Glucose transport is rate limiting for skeletal muscle glucose metabolism in normal and STZ-induced diabetic rats. Diabetes. 37:885-890.

9. Garvey, W. T., T. P. Huecksteadt, and M. J. Birnbaum. 1989. Pretranslational suppression of an insulin-responsive glucose transporter in rats with diabetes mellitus. Science (Wash. DC). 245:60-63.

10. Kahn, B. B., M. J. Charron, H. F. Lodish, S. W. Cushman, and J. S. Flier. 1989. Differential regulation of two glucose transporters in adipose cells from diabetic and insulin-treated diabetic rats. J. Clin. Invest. 84:404-411.

11. Sivitz, W. I., S. L. DeSautel, T. Kayano, G. I. Bell, and J. E. Pessin. 1989. Regulation of glucose transporter messenger RNA in insulin-deficient states. Nature (Lond.). 340:72-74.

12. Berger, J., C. Biswas, P. P. Vicario, H. V. Strout, R. Saperstein, and P. F. Pilch. 1989. Decreased expression of the insulin-responsive glucose transporter in diabetes and fasting. Nature (Lond.). 340:70-72.

13. Koranyi, L., D. James, M. Mueckler, and M. A. Permutt. 1990. Glucose transporter levels in spontaneously obese $(\mathrm{db} / \mathrm{db})$ insulin-resistant mice. J. Clin. Invest. 85:962-967.

14. Ramlal, T., S. Rastogi, M. Vranic, and A. Klip. 1989. Decrease in glucose transporter number in skeletal muscle of mildly diabetic (streptozotocin-treate) rats. Endocrinology. 125:890-897.

15. Koranyi, L., M. A. Permutt, J. M. Chirgwin, and S. J. Giddings. 1989. Proinsulin I and II gene expression in inbred mouse strains. Mol. Endocrinol. 3:1895-1902.

16. Chomcynski, P., and N. Sacchi. 1987. Single-step method of RNA isolation by acid guanidinium thiocyanate-phenol-chloroform extraction. Anal. Biochem. 162:156-159.

17. Peterson, G. L. 1977. A simplification of the protein assay method of Lowry et al. which is more generally applicable. Anal. Biochem. 83:346-356.

18. Rossetti, L., D. Smith, G. I. Shulman, D. Papachristou, and R. A. DeFronzo. 1987. Correction of hyperglycemia with phlorizin normalizes tissue sensitivity to insulin in diabetic rats. J. Clin. Invest. 79:1510-1515.

19. Wallberg-Henriksson, H., and J. O. Holloszy. 1985. Activation of glucose transport in diabetic muscle: responses to contraction and insulin. Am. J. Physiol. 249:C233-C237.

20. Dohm, G. L., E. B. Tapscott, W. J. Pories, D. J. Dabbs, E. G. Flinkinger, D. Meelheim, T. Fushiki, S. M. Atkinson, C. W. Elton, and J. Caro. 1988. An in vitro human muscle preparation suitable for metabolic studies. Decreased insulin stimulation of glucose transport in muscle from morbidly obese and diabetic subjects. J. Clin. Invest. 82:486-494.

21. Tordjman, K. M., K. A. Leingang, D. E. James, and M. Mueckler. 1989. Differential regulation of two distinct glucose transporter species expressed in 3T3-L1 adipocytes: effect of chronic insulin 
and tolbutamide treatment. Proc. Natl. Acad. Sci. USA. 86:77617765.

22. Kahn, B. B., E. S. Horton, and S. W. Cushman. 1987. Mechanism for enhanced glucose transport response to insulin in adipose cells from chronically hyperinsulinemic rats. Increased translocation of glucose transporters from an enlarged intracellular pool. J. Clin. Invest. 79:853-858.

23. Wardzala, L. J., M. Hirshman, E. Pofcher, E. D. Horton, P. M. Mead, S. W. Cushman, and E. S. Horton. 1985. Regulation of glucose utilization in adipose cells and muscle after long-term experimental hyperinsulinemia in rats. J. Clin. Invest. 76:460-469.

24. Kobayashi, M., and J. M. Olefsky. 1978. Long-term regulation of adipocyte glucose transport capacity by circulating insulin in rats. $J$. Clin. Invest. 62:73-81.

25. Brady, L. J., M. N. Goodman, F. N. Kalish, and N. B. Ruderman. 1981. Insulin binding and sensitivity in rat skeletal muscle: effect of starvation. Am. J. Physiol. 240:E184-E190.
26. Issad, T., L. Penicaud, P. Ferre, J. Kande, M. Baudon, and J. Girard. 1987. Effects of fasting on tissue glucose utilization in conscious resting rats: major glucose sparing effect in working muscles. Biochem. J. 246:241-244.

27. Stirewalt, W. S., R. B. Low, and J. M. Slaiby. 1985. Insulin sensitivity and responsiveness of epitrochlearis and soleus muscles from fed and starved rats. Biochem. J. 227:355-362.

28. Kahn, B. B., S. W. Cushman, and J. S. Flier. 1989. Regulation of glucose transporter-specific mRNA levels in rat adipose cells with fasting and refeeding. Implications for in vivo control of glucose transporter number. J. Clin. Invest. 83:199-204.

29. Kruszynska, Y. T., P. D. Home, and K. G. M. M. Alberti. 1987. Insulin insensitivity and skeletal muscle enzyme activities in response to overinsulinization in the rat. Metab. Clin. Exp. 36:281-285.

30. Penicaud, L., J. Kande, J. Le Magnen, and J. R. Girard. 1985. Insulin action during fasting and refeeding in rat determined by euglycemic clamp. Am. J. Physiol. 249:E514-E518. 